\title{
The Development Trend of the Medical Device Marketing
}

\author{
Jinguo Wang ${ }^{1, a}$, Corresponding Author: Na Wang ${ }^{2, b}$ and Yang $\mathrm{Gao}^{2}$ \\ ${ }^{1}$ Department of Urology, the First Hospital of Jilin University, China \\ ${ }^{2}$ Department of Anesthesiology, the First Hospital of Jilin University, China \\ awangjinguolily@163.com, bwangna080613@163.com
}

Keywords: Medical device, marketing, development, trend.

Abstract. The development trend of the medical device marketing is to promote the quality system. The establishment motive of the quality system is mainly according to national regulation and the necessary condition of being public and the secondary reason is the customers' requirements. Quickly to recruit industry experts by poaching talent is the key step into the medical device industry, saving time and cost.

\section{Introduction}

In terms of rules surface, according to the increasingly developed new technology and new use, laws and regulations in countries from development several lines gradually, not only in the world also gradually converged. New set of laws and regulations and the establishment of the new standard for the efficacy and safety of medical equipment guaranteed at the same time. Then through the power of the industry itself, it promotes industry gradually according to laws and regulations.

It is a technical and a word, the emergence of new technologies to drive the development of medical equipment, from simple to take care of to improve the medical care, will all areas of technology integration in medical apparatus and instruments, make originally not perfect medical system gradually tend to thanks to the progress of science and technology integration [1].

\section{Regulations of medical device industry in China}

Legal basis. Medical equipment management in mainland China started relatively late a lot in Europe and America, in, in the beginning of source.In the years of "regulations on the supervision and administration of medical devices" is the main source for the method of medical equipment management. To act as the main basis, derived a medical device registration, medical apparatus and instruments for examination and approval of new products, medical device manufacturing supervision measures for the administration of medical device manufacturing enterprise quality system assessment method, the classification rules of medical equipment, medical equipment manuals, labels and labeling regulations, and relevant regulation of derivatives such as all kinds of product registration regulations.

In the rules of logic and projects have been include the provisions related to medical apparatus and instruments, a slow than Europe and the United States, but to experience is most complete [2].

Government unit of management. Management unit is basically by the national health supervision and management organizations at all levels, respectively. Points' registration and assessment are the quality system.

The first kind of products is assessed by the municipal food and drug supervision and administration institutions.

The second category of products is monitored by provinces, autonomous regions and municipalities directly under the food and drug supervision and administration department.

The third category of products is monitored by the state food and drug administration review.

Foreign products by the state food and drug administration review [3]. 
The content of law. Medical equipment management architecture is in line with Europe and the United States, is also in pre-market review and post-marketing monitoring points in pre-market review process for the process is also the first classification, there are three kinds of Chinese medical equipment classification, in accordance with the structure characteristics of medical equipment, form and characteristics of judgment, and classification of made a son to divide it. Pre-market approval process below, divided into three stages, the process is clear, but there are several stages needed to have a long time, such as standard working hours is the third stage has reached more than a day, if add filling done, round-trip time often has more than three months.

Product review followed by quality system assessment, in accordance with the medical equipment management specification for assessment of the quality system. It is a specification for the 'medical equipment enterprise production conditions and the overall requirements of the production process. Classification formulated implementation guidelines for one type of product requirements, in accordance with the risk of the product is different, according to the active implantable medical devices and implantable medical devices, active medical devices, passive medical apparatus and instruments, sterile medical devices and in vitro diagnostic devices six categories were developed. Production detailed rules for the implementation that is specific for a particular item of medical equipment to make the implementation of the specification [4].

After the second city is in accordance with the announcement is about to further strengthen the supervision of medical device adverse event monitoring and regulation related matters. For medical device production enterprise must report suspicious medical device adverse events, and to take timely and effective products to take control of a security risk and intervention measures, to ensure security of the users to promote the quality system are motivated, mainly according to national regulation unit, also is the necessary condition of city permits secondary reason is that the customer requirements and the need to consciously. Respondents began to push this time is different, and there is no special trend, but once the drive of respondents can take certification within a year, in addition the or so in the next two years, only more than two years. In the process of promoting proportion pay for tutoring and no specific trend, depending on the number of companies and is due to the driving conditions caused by different.

\section{The development trend of medical equipment market}

\section{The development trend of medical equipment market has the following directions.}

High quality. High quality standardized commodities as the implementation regulations, the varieties of commodity quality management is more and more strict, listed by licensing requirements, product quality requirements will be relatively improve. For not have licensed medical material will be naturally eliminated by the market, under the condition of same quality products won a single rate will be higher than quality products to a company, so will gradually lead to product optimization.

Home care or maintenance center for dignity, will be a big trend, so in these places must have basic care facilities such as bed, breathing or force-fed equipment, general consumable medical materials, etc.

Aging society medical care. As medical technology advances, income increase and the nutrition is enough, in the absence of a gradual aging of the population trend, the old man some action inconvenience, but not to need special care, and must often provide physiological parameters to the hospital or clinic as a health tracking and home care needs and appear, such as blood pressure, blood sugar machine test records, such as more progress and through the network communication of monitoring instruments, etc [5]. Simple operation, the correct message is the biggest demand of the project.

Work and miniaturization in one another in the past often need to make more quantity in detect or repeat samples for many times, now some equipment has been integrated in one machine. 
Brought about by the development of new technologies, such as nanotechnology, anti aging beauty, auxiliary repair, information technology.

\section{The certification is not talisman}

Since the split between medical instrument by the drug, could not be tube gradually evolving legislation, in continuously revised perfect regulation system. Even now in a relatively long history in Europe and the us, its law still has a fixed discomfort.

Certification is required for both, the product of a valid quality assurance, but one in the management system can guarantee the safety of the medical equipment when use. But as the medical technology progress, with the discovery of new material and technology, the existing regulations, you have to the needs of the tide of new standards, therefore to recognize meter may have demand again. Or inexperienced or top can reference before, but now because of the experience accumulated after the new standards, products have city should test again.

And the advent of new products, while some standard reference, or to set up public security to detect all standard January, however, a problem occurs, all cannot escape responsibility. Most of the buyers already have risk consciousness and a cognitive, so there is no certification, may the customer doesn't even have to ask [6].

\section{Combining different industry abilities to create value.}

Medical equipment is a product of many industries, or the realization of the high-end technology in industries, such as the consumption of steel tubes, with the use of plastic injection or extrusion molding, technically similar to a water pipe, but on the list processing or its features more strict than the pipe. The purity of materials should be promoted, even require clean production environment, this is not only a general plastics factory can achieve. Such products need experienced plastic industry talents.

\section{The suggestions}

Suggestions for advanced company. Because laws and regulations increasingly rigorous and complicated, the previous marketing model could have a need to do this. The contract product line is a pure production attached more, smaller species sufficient reason should be toward the multifunction and high additional value product development. The trend of the products now forms the following qualities, that is small, portable or implantable, wireless transmission, multiple function and high reliability. With demand as the center, integration of diverse products in the same sales target.

Suggestions for the entrants. Quickly to recruit industry experts, in the analysis of the above mentioned many times, the settlements for medical devices industry since the late again, the industry experienced personnel is not a lot, so we want to from other related industries, and look for a person to not easy, even from the pharmaceutical or other biotech industry for, still takes a long time to develop, so can be quickly obtained in the form of poaching talent, is the key important step into the bank, saving time and cost for may.

Take shortcuts to replace development of mergers and acquisitions, purchase qualified or already listed on the existing products, can reduce the unnecessary waste of time, especially save listed verification time, tend to have years of gains. Borrow other derived from mergers and acquisitions and experience combined with its own industry expertise, to improve or develop new products can increase fast.

Careful consideration cost and risk, seemingly simple medical products or the price is low, the varying degree threshold. Sterile gauze piece, for example, the price is very low but involves disinfection sterilization need to have a professional operation, the strict control of the production, also need to do the packaging more standard is subject to inspection and specifications. Therefore into wood will most likely be more expensive than not sterilized gauze [7]. 
Government regulation. Constantly perfect law needs the new technology and new materials. With laws and regulations of more experience is still need to establish a complete database query and industry or law enforcement officers. This will be enough for a long time for this, is also in the future to accelerate the review and standardization of a vertical to work. Regulations between mixed with other countries, don't be selfish departmentalism, although free sex of harmonic current work unit, but each country ask demand still have differences, especially out private, affected by a country under the rule of law concept different often have more value, so the establishment of the database in the preceding paragraph and to participate in the international and opening up, will greatly catch up verification efficiency and cost savings.

Law enforcement rather than the scripted in risk management Angle, the emergence of many new products tend to be inconsistent with regulations, sometimes regulations are required, or change the original purpose. So validation of law enforcement personnel duty must improve the quality, especially with the concept of risk control for priority, to set the degree of risk control, need to rely on law enforcement professionals, at the request of the quality system, for example, to the product requirements need to be in control of the production environment in manufacturing, but many law enforcers must require operators will clean room, this is can increase the industry a lot of cost, personally think need key requirements depending on the production process of risk, rather than the whole production line are wrapped in a clean environment.

\section{Conclusions}

Some are already used in other aspects of the effect of improved technology can promote the medical material, reduce the patient's discomfort, endoscope, for example, from the original traditional way camera improvement become the optical fiber volume down, now have lubricant can reduce the patient's discomfort. These improvements are to rely on new technology or the invention of new materials, using improved diagnostic methods on all different industry combining with the results.

So want to want to innovative products for medical devices industry must have his heart, the core purpose in the middle, put the vision to other industrial technology. While other non-medical industry must focuses on the core technology through medical eye looking for a purpose.

Whether medical industry or outside the company, who want to enter and maintain the advantage in the health care industry must have appropriate talents. Talent is divided into general company regulations, sales, quality assurance, research and development, production and management, the most essential core is to establish the concept of risk management.

\section{References}

[1] Changying Sun, Shuyi Wang, Bingcao Wang. Ergonomic Design and Evaluation of Laparoscopic Instrument Handle Based on Anthropometry[A]. Proceedings of 2014 4th International Conference on Materials, Mechatronics and Automation(ICMMA 2014)[C]. 2014

[2] Jifeng Xu, Hanning Zhang, Zichao Nie. Office chair scales based on static sitting posture[A]. Proceedings of 2014 3rd International Conference on Electrical and Electronics Engineering(ICEEE 2014)[C]. 2014

[3] Ali Faraji, Morteza Rohani Farahmand. An Ergonomic Computer Mouse for Professional Designers[A]. Proceedings of 2013 International Conference on Advanced Materials \& Sports Equipment Design(AMSED 2013)[C]. 2013

[4] Hui Kang, Yong Wang, Shuo Zhou. The Application in Product Design Based on the Function of KATIA V5R21 Man-machine Engineering[A]. Proceedings of 2015 3rd International Conference on Social Science and Education(ICSSE 2015 V74)[C]. 2015 
[5] TIAN Xiang Ke, GUO Chun Feng, YANG Jun. The Modeling and Optimization Design of Multifunctional Movement Wheelchair Based on Ergonomics[A]. Proceedings of 2015 Joint International Mechanical,Electronic and Information Technology Conference(JIMET 2015)[C]. 2015

[6] Tiecheng Zhang. The implications of digital human models in ergonomics virtual maintenance[A]. Proceedings of 2014 3rd International Conference on Electrical and Electronics Engineering(ICEEE 2014)[C]. 2014

[7] Alessandro Naddeo, Nicola Cappetti, Rosaria Califano, Mariarosaria Vallone. Manual Assembly Workstation Redesign Based on a New Quantitative Method for Postural Comfort Evaluation[A]. Proceedings of 2013 4th International Conference on Applied Mechanics and Mechanical Engineering(ICAMME 2013)[C]. 2013 